\title{
Study on Epoxy Nanocomposites Viscoelastic Properties through Dynamic Shear Rheological Analysis Method
}

\author{
Chillakuru TR ${ }^{1}$, Khan WS $^{2}$, Uddin MN $^{1}$, Ibrahim M Alarifi ${ }^{3}$ and Asmatulu $\mathbf{R}^{1 *}$ \\ ${ }^{1}$ Department of Mechanical Engineering, Wichita State University, USA \\ ${ }^{2}$ Department of Mechanical Engineering, Fujairah Men's College, UAE \\ ${ }^{3}$ Department of Mechanical and Industrial Engineering, Majmaah University, Saudi Arabia
}

Submission: June 16, 2021; Published: July 06, 2021

*Corresponding author: Asmatulu R, Department of Mechanical Engineering, Wichita State University, USA

\begin{abstract}
Some extraordinary determinations have been made to investigate the epoxy-based nano-composite properties and the viscoelastic curing kinetics for several different industrial applications, such as aircraft, wind energy, defense, and automotive applications. In this research work, the rheological properties of epoxy-based nano-composites containing altered percentages $(0 \%, 1 \%, 2 \%, 4 \%$ ) of nanoparticles (such as carbon $[\mathrm{C}]$ and zeolite) were investigated by utilizing a dynamic shear rheological analyzer. Here, the curing kinetics of commercially available thermosetting epoxy resin (Loctite EA 9394 Aero) was studied in detail. It was found that the addition of nanoparticles, such as CB and zeolite in varying proportions $(0 \%, 1 \%, 2 \%$, and $4 \%$ ) significantly improved the viscoelastic properties and the curing kinetics (storage modulus, loss modulus, and $\tan \delta$ ) of the nano-composites, which may be helpful in better product development in those industries in the future.
\end{abstract}

Keywords: Carbon Black; Zeolite; Nanocomposites; Rheological Analysis; Viscoelastic Properties

\section{Introduction}

Investigators have been examining various options to improve the mechanical properties, thermal permanence, and resistance against epoxy nano-composites environmental degradation, by incorporating different types of filler materials with the epoxy resin [1-3]. Epoxy resins are extensively used in fiberreinforced composites due to their excellent thermal, electrical, and mechanical properties. Conditional on the curing kinetics and composition, it can alter their mechanical properties, such as increasing flexibility, and physical and strength properties, such as adhesive strength, chemical and electrical conductivity, and heat resistance [4-6]. The inescapable epoxy thermosets used are limited in various high-performance applications due to their brittleness, delamination, insufficient endurance, low impact resistance, and low fracture toughness. The development of high-performance composites based on thermosetting polymers can be realized by concomitantly improving the fiber, resin, and interphase properties. Numerous attempts have been made to address the shortcomings of epoxy resins by using additives and modifiers. One of the most effective ways to address the low fracture toughness issue is by adding thermoplastics, elastomers, nanoparticles, and core-shell particles [7-8]. The most successful method for toughening epoxy resins is to incorporate distributed thermoplastic and elastomeric segments into the resin, which generally creates a multiphase polymeric structure [9]. However, these techniques typically do not deliver enough improvement in toughness for highly cross-linked epoxies, high glass transition temperatures, and their composites.

An innovative method for enhancing composites' mechanical properties is the use of nanosized inorganic and organic particles. Due to the nanosize of reinforcements, polymer nano-composites present the prospect of developing novel materials with exotic properties. These nanoparticles are considered to be promising filler materials for improving the physical properties and the mechanical function of unusual properties, which has resulted in extensive research activity in engineering and technology. In addition, the development of nanosized particles into polymers has recently been paid attention in the materials discipline and engineering in order to progress functional nano-composites that 
offer improved properties; in comparison to predictable polymerbased composites that contain micro-scale particulates, for example, carbon black (CB) or glass microspheres. The nanofillers used in this study are CB and zeolites. Carbon black is a black powder that works as a pigment and property-enhancing agent in a wide range of composite materials. It possesses some exceptional properties, which makes it a valuable part of composite materials. These properties include ultraviolet protection, high electrical conductivity, and high surface area. Zeolites are crystalline microporous aluminosilicates generally found on the earth's surface, such as hydrothermal alteration products, soil, seafloor deposits, sediments, changed volcanic deposits, and so on [10].

Dynamic shear strain and stress are essential factors in the rheological study of nano-composites. The relationship between dynamic shear strain and stress within a viscoelastic region is shown [11] as:

$$
\left|G^{*}\right|=\frac{\tau_{o(t)}}{\gamma_{o}}
$$

Where $\tau_{o(t)}$ is the maximum dynamic shear stress, or stress

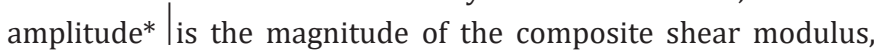
and $\gamma_{o}$ is the maximum strain amplitude, or dynamic shear strain. Moreover, the strain energy of a disfigured structure can be estimated using the area under the curve (stress curve) in the stress-strain figure. In this study, a strain-directed rheometry experiment was performed within the viscoelastic zone, where $\gamma_{o}$ is constant for every oscillation, $\left|\mathrm{G}^{*}\right|$ is the calibration of the system the total strain energy within every oscillation, and $G^{\prime}$ and $G^{\prime \prime}$ are associated with $G^{*}$ by the rudimentary formulations of viscoelasticity:

$$
\begin{array}{r}
G^{\prime}=\left|G^{*}\right| \cos (\gamma) \\
G^{\prime}=\left|G^{*}\right| \sin (\gamma) \\
G^{*}=\sqrt{\left(G^{1}\right)^{2}+\left(G^{\prime \prime}\right)^{2}}
\end{array}
$$

Where $\delta$ is defined as the stage lag or phase angle, between the stress and the dynamic shear strain, materials having a lower viscosity possess a larger $\delta$. The extent of the cure properties $\left(G^{\prime}\right.$ $\left.G^{\prime}\right)$ was normalized by $\left|G^{*}\right|$ as:

$$
\begin{aligned}
& G_{n}^{\prime}=G^{\prime} /\left|G^{*}\right|=\cos (\delta) \\
& G_{n}^{\prime \prime}=G^{\prime} /\left|G^{*}\right|=\sin (\delta)
\end{aligned}
$$

The objectives of the study were to examine the curing kinetics of commercial epoxy resin using a shear rheometer, the effects of nanoparticles on curing kinetics, and how to improve the viscoelastic properties of composites with good dispersion of nanoparticles.

\section{Experiment}

\section{Materials}

The resin material used in this experiment is a commercial thermosetting epoxy resin by Henkel Inc. The matrix system involves Loctite EA 9394 Aero and typically a two-part adhesive paste (Parts A and B), which cures at room temperature (3-5 days at $77^{\circ} \mathrm{F}$ ). This resin system has excellent bonding strength at $350^{\circ} \mathrm{F} / 177^{\circ} \mathrm{C}$. Because of the thixotropic nature of this system and the elevated temperatures involved, the resulting compressive strength makes it an ideal selection for the liquid shim, potting and filling applications. This resin system is known for its outstanding mechanical properties, excellent gap-filling capabilities, room temperature storage, long pot life, and low toxicity. Loctite EA 9394 Aero can be mixed by weight ratio and volume ratio. This resin was blended in a 100:17 weight ratio of Parts A and PB. The reinforcement/fillers used were carbon black (20 96 nm) and zeolite $(8 \sim 12 \mathrm{~nm})$, manufactured by Cabot and Zeolyst International, respectively. Zeolites are formed by hydrothermal synthesis, generally under mild conditions, and synthetic conditions govern the nature of zeolite, that is, temperature, $\mathrm{pH}$, time, reactant concentrations, and so on [12].

\section{Method}

Samples were prepared using the wet layup process where the resin and hardener systems were mixed according to the manufacturer's specification, a ratio of 100:17. The prepared mixture was allowed to sit in an 0 ring $(41 \mathrm{~mm}$ ) made of silicone in order to sustain a high temperature of around $250^{\circ} \mathrm{C}$. The samples were $3 \mathrm{~mm}$ average thickness and $5.40 \mathrm{~g}$ average weight. Figure 1 shows the steps in the fabrication of the nano-composite. First, the epoxy resin, hardener, and nanoparticles were weighed on a weighing scale. The weighted mixture was mixed well with a high-speed homogenizer. An O-ring was placed on a Kapton film and filled with the prepared mixture. The top surface was made even and smooth before placing a Kapton film on the top of the assembly. The sample was then placed in a shear rheometer. After approximately three hours, the sample was entirely cured. A minimum of three tests were conducted, and the test outcomes were averaged for each data point.

\section{Rheological mensuration}

The rheological characteristics and cure performance of the resin system (Loctite EA 9394 Aero) were processed according to the following ASTM test methods [13]:

a. ASTM E1640-04: Standard Test Procedure for the Glass Transition Temperature the Assignment by Dynamic Mechanical Analysis.

b. ASTM D4065-01: Standard Application for Plastics: Mechanical Properties: Procedures Report and Determination.

c. ASTM D4473-03: Conventional Test Method Plastics: Mechanical Properties: Cure Behavior.

\section{Results and Discussion}

The cure properties of polymeric materials can be defined by employing the viscoelastic properties, such as dynamic shear

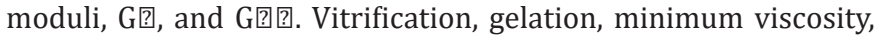
and a plateau zone are phenomena that occur during epoxy resin 
curing. Viscoelastic materials display both viscous and elastic effects when they undergo deformation, and they exhibit a timedependent strain. The curing of polymeric materials occurs in the manufacturing process, wherein the thermoset resins are transformed from a liquid to a solid state. The mechanisms involved during curing are compound and difficult to understand. During curing, heat is produced because most of the polymerization of thermoset reactions is exothermic. The polymeric material finally changes from its vitrified glassy state and initial liquid state to a rubbery gel. The resin consists of very short-chain monomers in liquid form. At elevated temperatures, especially in the presence of individual agents, the monomers begin to bond with adjacent monomer molecules, which signals the beginning of curing. Hardeners are used to facilitate monomer to monomer bonding by shearing hydrogen bonds, and a process generally referred to as protonation. Once the molecules begin protonating, they keep increasing in length in order to eventually transform into long chains with some degree of free body motion - enough to slide past each other. However, this motion is limited when compared to the degree of freedom available in the unreacted state. As the curing process continues, the chains become longer and longer, until a point is reached where protonation slows down [14].

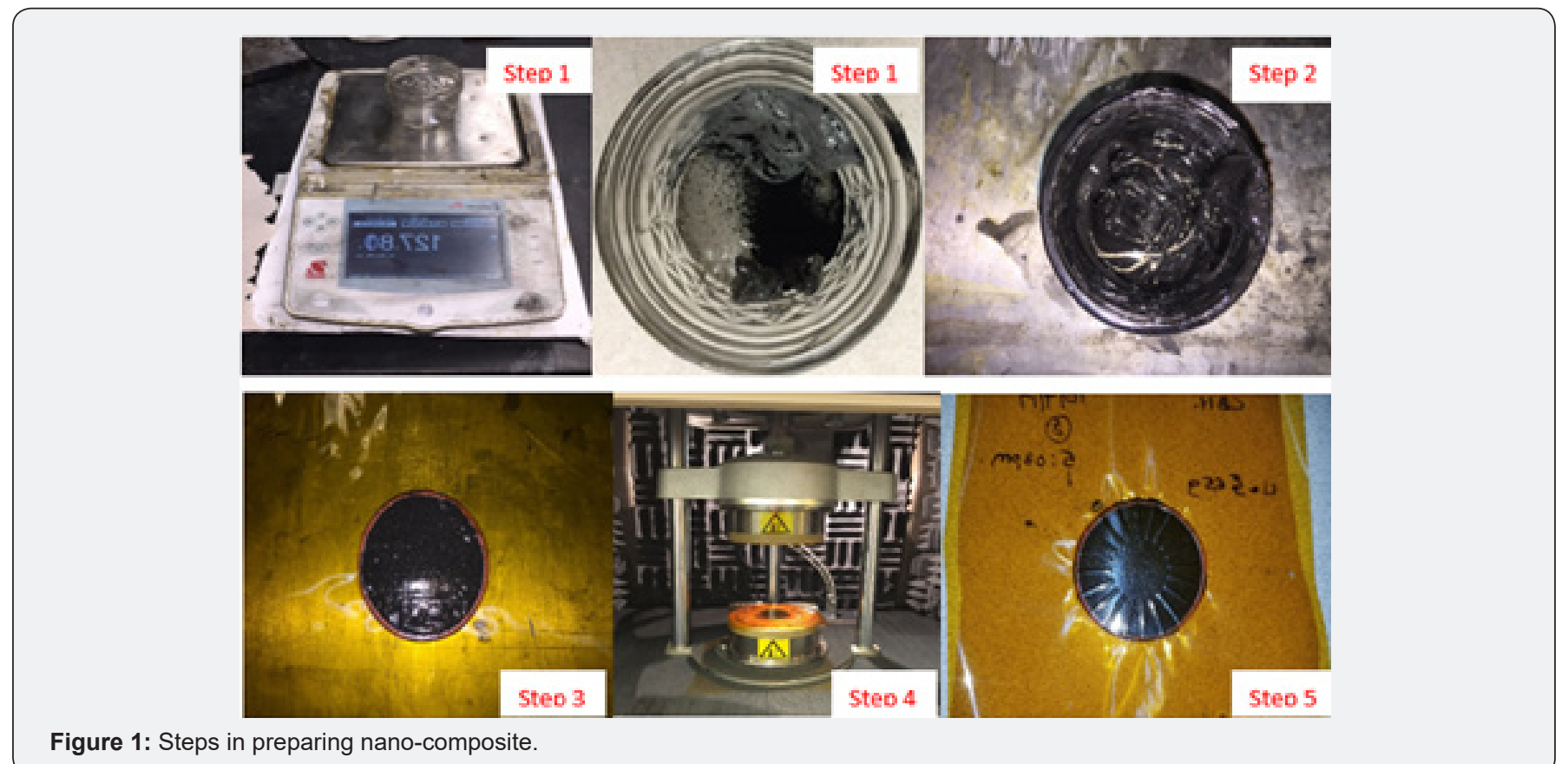

At this stage, a phenomenon known as the nucleophilic reaction occurs, whereby the chains begin to bond with adjacent chains utilizing two mechanisms: van Der walls forces, which bring the chains together through the molecular attraction, and the formation of complexes, which facilitate curing. As a result, the chains become interlinked together, forming a dense threedimensional network that continues to form until there is enough energy and free-body motion. At this stage, it is assumed that the material is now theoretically cured, and both the curing viscosity and chain length increase. The point where the protonation reactions slow down, and complex formation begins can be seen as the sharp increase in the viscosity of the resin, almost to the point of infinity. This stage can be regarded as the point of gelation of the resin [15], where the material is somewhat rubbery. As the complex formation continues, the material slowly transitions from a rubbery state to a solid glassy state, appropriately termed as vitrification. Next, the secondary complex formation slows down, the curing rate slowly declines, and the material is vitrified into a final solid form. Very little research on the viscoelastic properties in curing thermosets has been carried out. Some work has focused on the relationship development between viscoelastic properties and parameters, for example, the molecular weight, molecular weight dispersal, and polymer chain branching degree $[16,17]$. The application of an ultrasonic wave to a material acting as a high-frequency oscillatory excitation can deliver data concerning the viscoelastic behavior of polymers [18].

Some researchers have used dielectric spectroscopy to examine the characterization of curing polymers by using ionic mobility to dynamic viscosity [19]. Suzuki et al. gathered relaxation data for epoxies that cured, allowing various cure cycles without finding the cure states of samples [20]. Information on these parameters is essential in analyzing and determining various attributes, for example, void contented, and thermal and mechanical composite properties. Consequently, the ultimate characteristics of the composite can be enhanced by altering the cure profile (temperature and pressure). Plazek and Chay calculated the viscoelastic properties in an epoxy resin both below the gelation point and above [21]. They prepared completely cured models by varying the ratio of monofunctional and tetra 
functional curing agents in a stoichiometric epoxied curing agent mixture. This method allowed the scientists to determine fixed points in the network's development properties. However, each specimen network is different, and a straight relation to the cure degree is almost impossible. The cure degree is generally defined as:

$$
\alpha=\frac{H(t)}{H(U)}
$$

Where $\mathrm{H}(\mathrm{t})$ The heat is out of the crosslinking response until time " $\mathrm{t}$," and $\mathrm{H}(\mathrm{U})$ is the ultimate heat response. Figures $2 \& 3$ show different cure events in a graph of GQ? and G? 0 ? over time. Generally, the storage modulus is increased by increasing the nano additives, and elastic properties are improved at elevated temperatures [22]. The storage modulus delivers essential information about the structure that is present in a material. It generally characterizes the energy stored in the elastic sample structure. If it is developed more than the loss modulus, then the material could be regarded as elastic. The loss modulus represents the viscus part or the degenerate energy amount in the sample. The sum of the loss and storage modulus is identified as the complex modulus. As shown in Figures 2 \& 3, the minimum viscosity zone involves the curing process in the early stages. In the initial temperature range, there is no crosslinking between molecular chains. After the initial stages, polymer macromolecules are formed, and the crosslinking of molecular chains is still low due to their high mobility. This results in a steep rise in the viscosity of the nano-composite. Next, gelation of the epoxy system begins, and a three-dimensional cross-linked molecular chain with infinite viscosity is formed. Gelation-associated macromolecular chains subsequently result in a branched polymer formation, or the transformation from a structure with finite separated polymers to infinite molecules with a solubility related to the starting material's chemical nature [23].

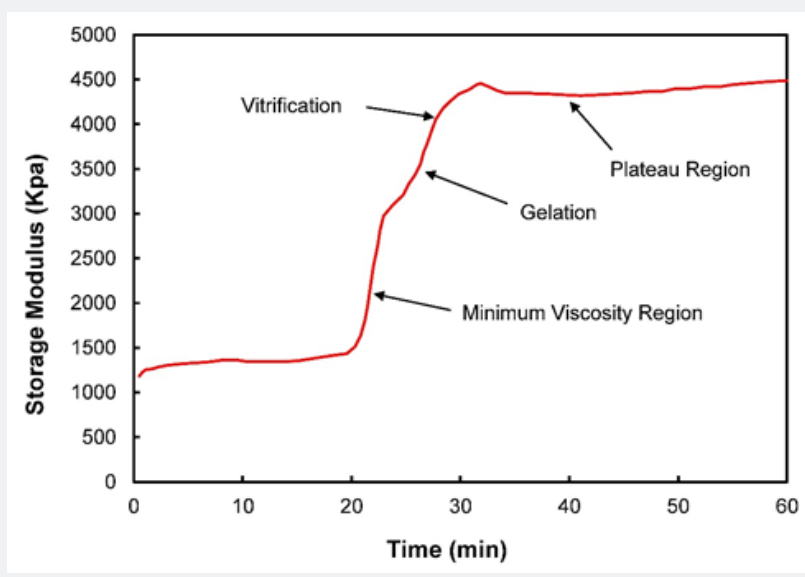

Figure 2: The storage modulus $\left(G^{\prime}\right)$ variation with cure time.

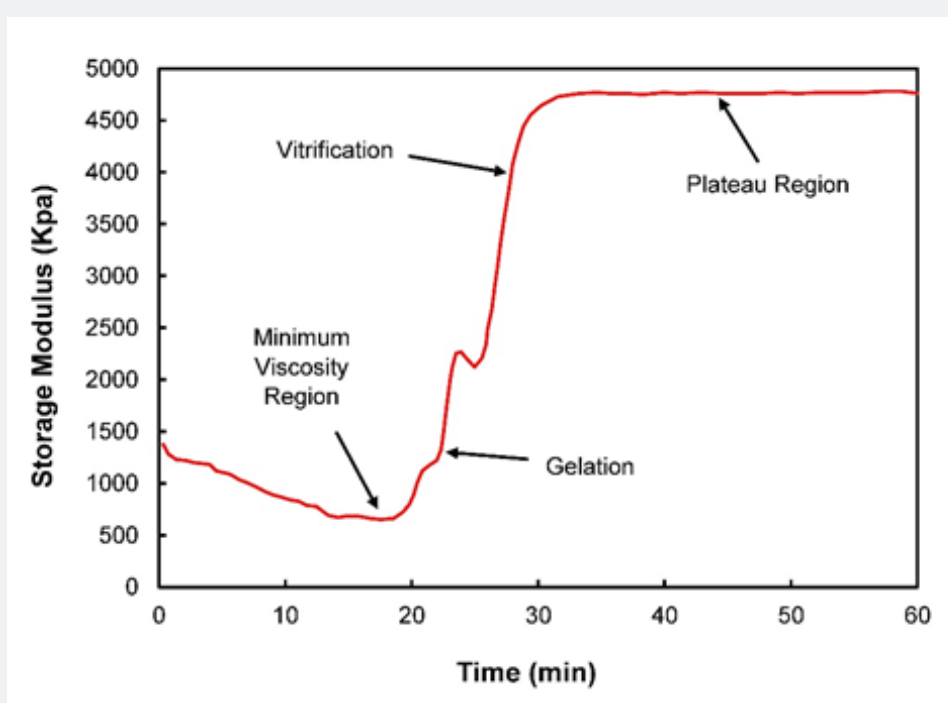

Figure 3: The loss modulus (G' ') variation with cure time. 
During gelation, the curing reaction transforms the molecular weight to its maximum, generally assumed to be infinite [24]. Gelation is a microscopic effect that produces macroscopic results. Gelation transforms the liquid into a rubbery state, which is a non-return point in the cure. Gelation is followed by vitrification, during which the rubber state is transformed into a glass state, and the polymerization reaction stops. Vitrification modifies a viscous modulus to an elastic modulus. Beyond vitrification, the composite material/resin system does not undergo any significant change. As a result, the cure characteristics move towards a plateau area where an infinite network structure is formed, and the composite is fully cured. The crosslinked network provides the composite with high rigidity, high strength, excellent thermal and oxidative capabilities, and resistance to solvents. Isothermal cure tests were conducted at a constant temperature of $93^{\circ} \mathrm{C}$ with an increment of $1.68^{\circ} \mathrm{C}$ by employing an ATD 2000 shear rheometer in order to determine the Loctite EA 9394 Aero epoxy viscoelastic properties. In Figure 4, the cure profile is plotted between the average temperature and the average time for all the samples used in this study. The temperature was increased slightly from $43^{\circ} \mathrm{C}$ to $92^{\circ} \mathrm{C}$ at a rate of $1.68^{\circ} \mathrm{C} / \mathrm{min}$ for 30 minutes to attain the isothermal cure temperature. The specimens were held at $93^{\circ} \mathrm{C}$ for almost 2 hours and then cooled down rapidly at a rate of $-1.77^{\circ} \mathrm{C} / \mathrm{min}$ for 30 minutes to avoid degradation of the material. As shown in Figure 4, the cure profile followed the same pattern for all samples.

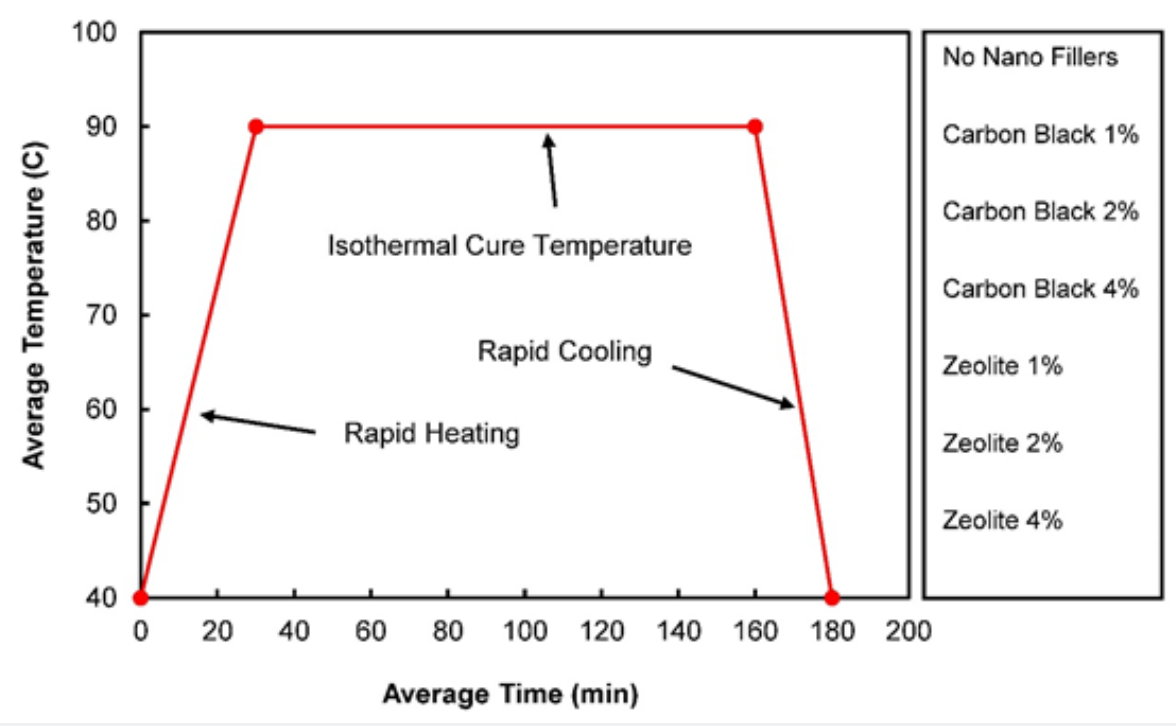

Figure 4: Variation in temperature $($ Tcure $=93 \square)$ with time for all specimens.

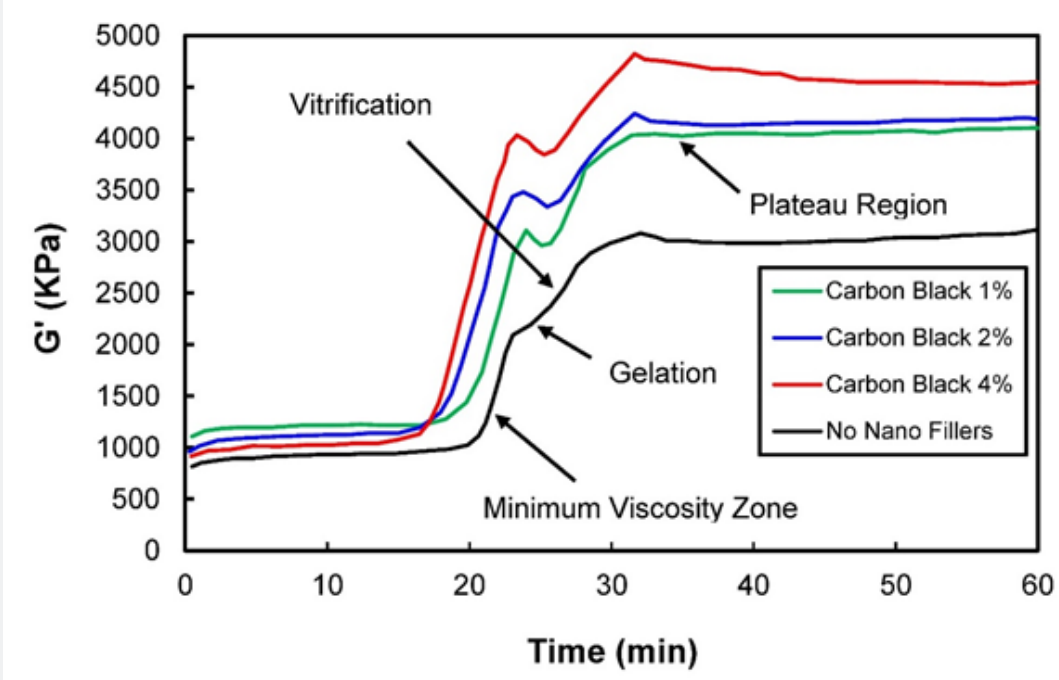

Figure 5: The storage modulus variation in time for different $C B$ percentages in neat epoxy resin. 
Figure 5 displays the variation in the composite storage modulus with time having various weight percentages of carbon black in the epoxy resin. It can be seen that the cure profile is almost identical for all samples. Slightly different cure events were observed with an increase in temperature. The material first experienced the minimum viscosity within 20 minutes. Later, the material transformed from a liquid to a gel (gelation). Once the material achieved the isothermal cure temperature $\left(92^{\circ} \mathrm{C}\right)$, the cure properties moved towards the plateau region, thereby transforming into a glassy structure (vitrification). The addition of a non-additive to the epoxy resin reduced the mobility of the polymer chains, which is principal to an increase in modulus values [25]. This consequence was more noticeable in the glass transition region. After the vitrification stage, the storage modulus reshaped itself to the plateau region, thereby forming an infinite network of polymer chains, which is referred to as a fully cured composite structure. Finally, the material was allowed to cool in order to avoid degradation. The existence of a non-additive in the epoxy resin plays an important role in cure kinetics

Figure 6 shows the nano-composites variation storage modulus with different concentrations of zeolite nanoparticles in the epoxy resin system. It is apparent from Figure 6 that zeolite nanoparticles in the epoxy resin system exhibited an almost similar trend that was observed with carbon black nanoparticles in the epoxy system. As the zeolite nanoparticles percentage increased, the composite tended to store more energy. In both cases, the addition of nano additives facilitated the improvement of the composite's mechanical properties. Figures $7 \& 8$ show the loss modulus of the nano-composite with different percentages $(1 \%, 2 \%$, and $4 \%)$ of CB and zeolite nanoparticles, respectively. It can be concluded from Figure 7 that as the weight percentage of $\mathrm{CB}$ increases, higher energy is dissipated. Figure 8 shows various trends for different percentages $(1 \%, 2 \%$, and $4 \%)$ of zeolite nanocomposites. Interestingly, the energy released as heat dropped with the increase in the percentage of nanofillers in the epoxy resin, but managed to stay above the epoxy (0\% nanofillers) curve. Figures $7 \& 8$ reveal various cure events like minimum viscosity region, gelation, plateau region, and vitrification, and these measures occurred almost in a similar fashion to the storage modulus explained previously.

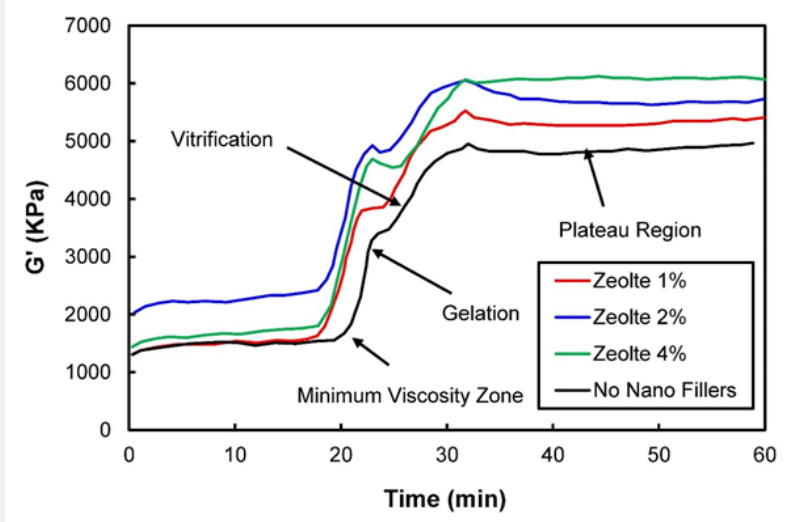

Figure 6: The storage modulus variation in time for different zeolite percentages in neat epoxy resin.

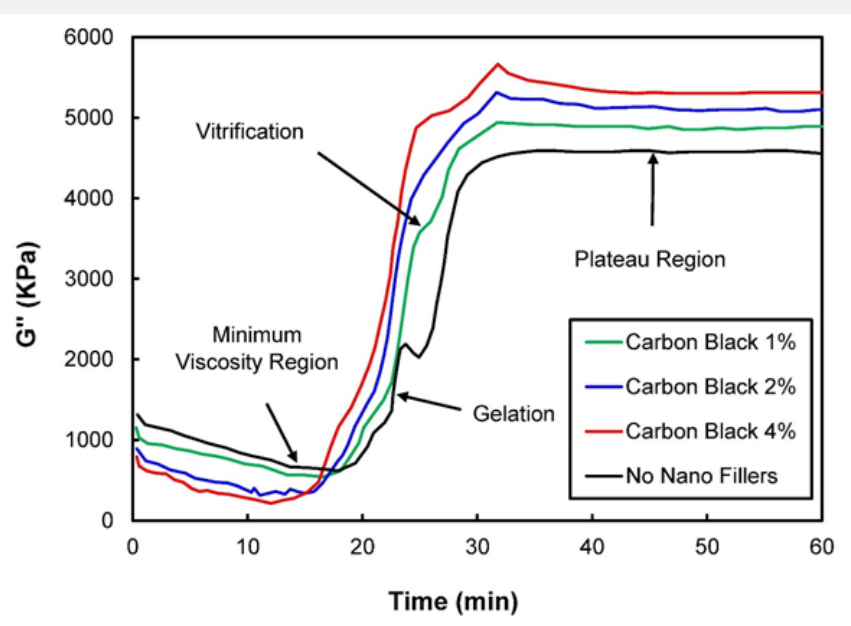

Figure 7: The loss modulus variation in time for different СB percentages in neat epoxy resin. 


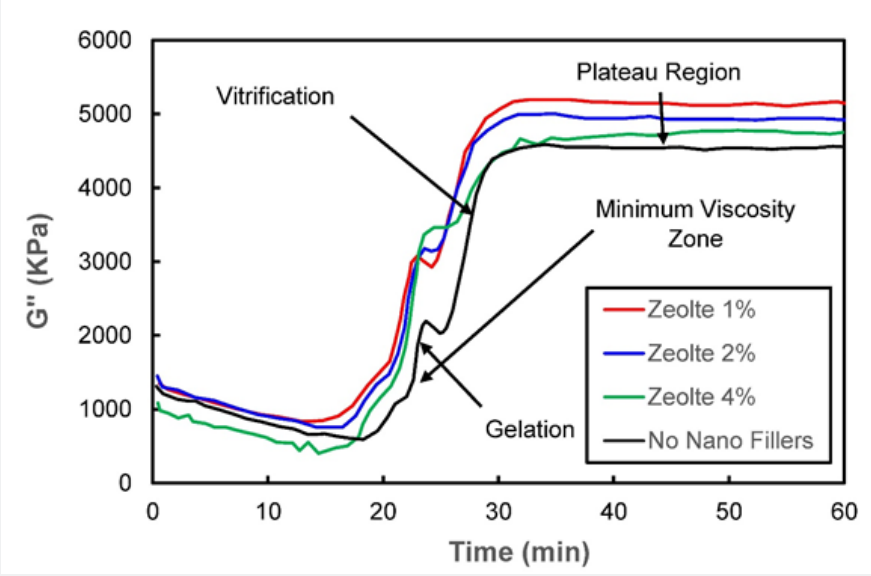

Figure 8: The loss modulus variation of in time for different zeolite percentages in neat epoxy resin.

The loss modulus and storage modulus of carbon black nano-composites (shown previously in Figures 5 \& 7) were investigated. It was determined that the material tends to absorb and release more energy, thus making nano-composites a viscoelastic material. The storage modulus delivers data about the energy stored in the material elastic structure, and the loss modulus represents the viscous part of the energy dissolute in the material. Examining Figures 6 \& 8, shown previously, reveals that more energy was stored, and less energy was dissipated in the zeolite-based samples. This clearly indicates that the composite material is not a viscoelastic material. The decrease in loss modulus with the increase in zeolite content could be attributed to the fact that zeolite nanoparticles chemically react with resin molecules. Figures $9 \& 10$ show the damping coefficient or tangent of delta (Tan delta) of nano-composite materials varies with different weight percentages of nano additives. All plots have been compared with neat epoxy resin as a base system. Tan delta measures the dampening of the material. Figure 9 illustrates how the damping of carbon black nano-composites behaves with different percentages $(1 \%, 2 \%$, and $4 \%$ ) of nano additives over time. Tan $\delta$ (damping coefficient) is the loss modulus ratio to storage modulus: the higher the $\tan \delta$ value, the more enhanced the damping properties. Damping properties are improved with the addition of nano additives.

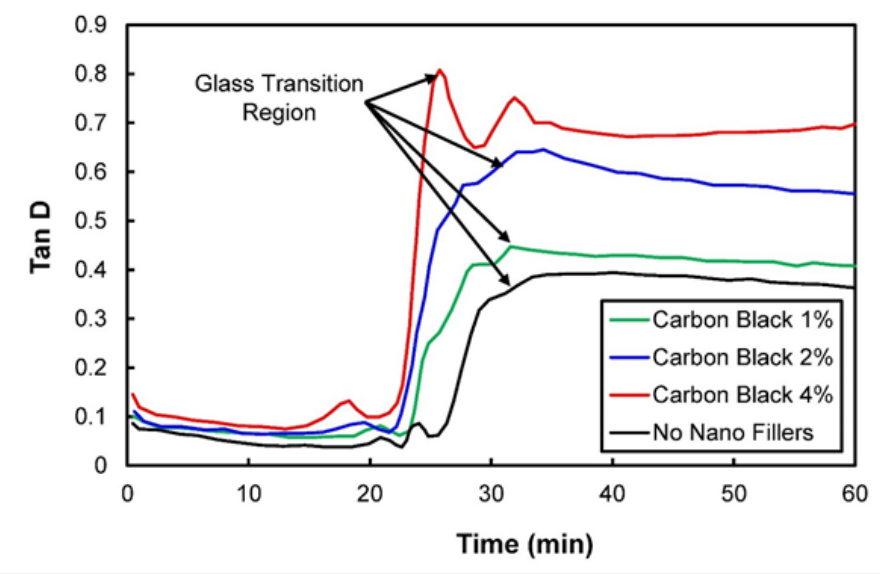

Figure 9: The damping index variation in time for different CB percentages in neat epoxy resin.

It can be inferred from the plot in Figure 9 that the higher percentages $(4 \%)$ of CB indicate the good dampening coefficient of the material. The highest peaks in each curve represent the glass transition. A material with $\tan \delta=1$ is assumed to be a perfectly viscoelastic material. Interestingly, in the present study, the dampening effect of CB nano-composites is closer to unity with the higher percentages of fillers. Similarly, Figure 10 shows the influence of zeolite nanoparticles in the dampening effect. Surprisingly, zeolite nano-composites experience higher damping coefficients at higher percentages of nano additives. The glass 
transition can be identified by spotting the peaks in the curves individually. These materials can be designed better with excellent viscoelastic properties by augmenting and optimizing the nano additive percentages. Many researchers have examined the thermosetting materials' viscoelastic response near the gel point [26-28]. Plazek and Chay reviewed the evolution of viscoelastic properties in the gelation below the point and an epoxy resin above [21]. Heat generation due to crosslinking and thermal asymmetry may result in uneven curing kinetics. Epoxy resins can shrink about $6 \%$ during curing. The matrix performance is temperature-dependent and spans the entire range of liquid to solid during processing. Mitchell et al. studied composite linear viscoelastic properties using pristine single-walled carbon nanotubes (CNTs) and originally modified single-walled CNTs in a polystyrene matrix [29].

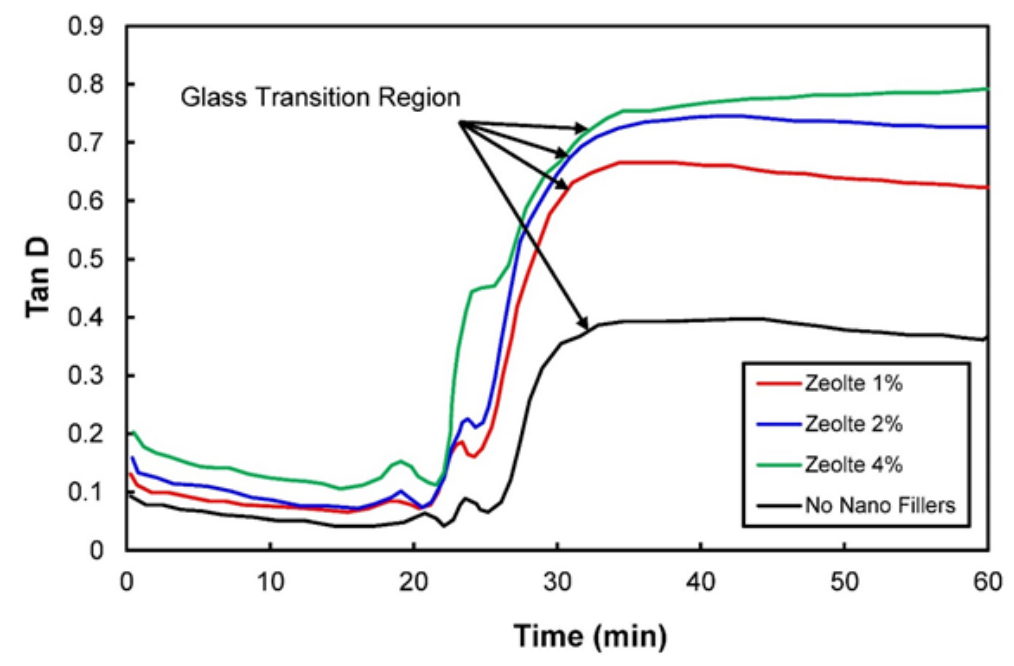

Figure 10: The damping index variation in time for different zeolite percentages in neat epoxy resin.

They established that the nanotubes with functional groups are better dispersed in polystyrene than those without functional groups. They similarly found that the nano-composite with functionalized nanotubes possessed a better complex viscosity and storage modulus at the low-frequency level. Salam at el. studied the multi-walled CNTs' viscoelastic properties and epoxy resin composites by employing two altered curing cycles, and found that composite and pure epoxy samples are affected by the condition of the curing process [30]. Kim et al. calculated epoxy resin's rheological behavior when it contained amine, plasmatreated CNTs, and acid [31]. They found that the epoxy/surfacemodified CNT displayed good shear thinning performance and higher shear viscosity than those with untreated CNTs due to the improved epoxy resin and interfacial bonding between CNTs. Song and Youn conducted comparable research work and determined that poorly dispersed CNTs within epoxy resin lead to a loss modulus, complex viscosity and higher storage compared to homogeneously dispersed CNTs [32,33].

\section{Conclusion}

Epoxy nano-composites containing various carbon black weight percentages and zeolite were fabricated in this study. The rheological properties of nano-composites were investigated by the dynamic shear rheological analyzer. It was found that the addition of nanoparticles significantly altered the curing kinetics, and changes were noticed in the loss modulus, storage modulus and $\tan \delta$. The viscoelastic properties, such as storage modulus, were found to absorb more energy in both the CB and zeolite nanocomposites at higher concentration levels of nano fillers than the neat epoxy resin system. The material became more elastic dominant than vicious because, at this point, $G^{\prime}$ is larger than $G^{\prime}$. The sheer loss modulus of the carbon black nano-composite increased with a higher concentration of nano additives. At this point, the loss modulus dominated the storage modulus because the force applied was larger than the force required to deform the body; thus, the materials tend to dissipate more energy resulting in material flow. In another case, the shear loss modulus for the zeolite nano-composite was found to drop with an increase in the weight percentages of the nano additives. It was determined that zeolite was less viscous and more elastic dominant. This shift in the properties associated with $\mathrm{CB}$ could be attributed to the chemical reactions of zeolite with epoxy resins. Finally, it has been demonstrated in this study that the CB nano-composite displayed viscosity - an elastic property that makes the composite material ideal for many applications. The zeolite-based nano-composites were found to be more elastic than viscous. In this study, both $\mathrm{CB}$ and zeolite nano-composites tended to have good damping coefficients close to unity. Therefore, it is recommended to adjust 
the weight percentages of nano additives greater than or equal to $4 \mathrm{wt} \%$, or equal to an optimal percentage, in order to accomplish damping ratios very close to unity. An excellent dampening material has a wide range of applications, such as automobile, aerospace, and aircraft structures.

\section{Acknowledgment}

The authors impressively acknowledge the National Institute of Aviation Research for financial and Wichita State University for the technical support of the current research work.

\section{References}

1. Hosur M, Mahdi TH, Islam ME, Jeelani S (2017) Mechanical and viscoelastic properties of epoxy nano-composite reinforced with carbon nanotubes, nanoclay and binary nanoparticles, Journal of Reinforced Plastics and Composites 36(9): 667-684.

2. Kumar SSA, Uddin MN, Rahman MM, Asmatulu R (2018) Introducing graphene thin films into carbon fiber composite structures for lightning strike protection, Polymer Composites 40(S1): E517-E525.

3. Uddin MN, Le L, Zhang B, Nair R, Asmatulu R (2019) Effects of Graphene thin films and nano-composite coatings on fire retardancy and thermal stability of aircraft composites: A comparative study. Journal of Engineering Materials and Technology 141(3): 031004.

4. Njuguna J, Pielichhowski K, Alcock JR (2007) Epoxy-based reinforced nano-composite: current status, Advanced Engineering Materials 9(10): 835-847.

5. Uddin MN, George JM, Asmatulu R (2019) Investigating the effects of UV light and moisture absorption on the low impact resistance of three different carbon fiber-reinforced composites. Advanced Composites and Hybrid Materials.

6. Uddin MN, Gandy HTN, Rahman MM, Asmatulu R (2019) Adhesiveless honeycomb sandwich structures of pre-preg carbon fiber composites for primary structural applications. Advanced Composites and Hybrid Materials 2(2): 339-350.

7. Blano G, Cicala C, Faro A, Recca A (2003) Improvement of thermomechanical properties of a DGEBS/DDS system blended with a novel thermoplastic copolymer by realization of a semi-IPN network. Journal of Applied Polumer Science 88(13): 3021-3025.

8. Dodiuk H, Kenig S, Blinsky I, Buchman A (2005) Nanotailoring of epoxy adhesives by polyhedral-oligomeric-sil-sesquioxanes (POSS). International Journal of Adhesion and Adhesives 25(13): 211-218.

9. Visakh MP (2016)Nanomaterials and Nano-composites: Zero- to three-dimensional materials and their composites, 2016 Wiley-VCH Verlag GmbH \& Co. KGaA.

10. Zhou J, Hua Z, Liu Z, Wu W, Zhu Y, et al. (2011) Direct synthetic strategy of mesoporous ZSM-5 zeolites by using conventional block copolymer templates and the improved catalytic properties, ACS Catalysis 1(4): 287-291.

11. Chillakuru TR, Uddin MN, Asmatulu R (2018) Investigating the viscoelastic properties and curing kinetics of thermoset Nanocomposites via dynamic shear rheological analysis, The composites and advanced materials Expo. CAMX Conference Proceedings, Dallas, USA.

12. Pan T, Wu Z, Yip ACK (2019) Advances in the green synthesis of microporous and hierarchical zeolites: A short review. Catalysts 9(3): 274.
13. Soltani S, Sabzevahri S, Mousavi A, Minaie B (2009) "Modeling the gelation and vitrification points for polymer composites using shear rheometry," SAMPE, Baltimore, USA.

14. Saseendran S (2016) Effect of degree of cure on viscoelastic behavior of polymers, Licentiate Thesis, Department of Engineering Sciences and Mathematics, Lulea University of Technology, Sweden.

15. Lionetto F, Maffezzoli A (2013) Monitoring the cure State of Thermosetting Resins by Ultrasound. Materials 6(9): 3804.

16. Apostolidis P, Liu X, van-de Ven M, Erkens S, Scarpas T (2019) Kinetic Viscoelasticity of crosslinking epoxy asphalt, Transportation Research Record 2673(3): 551-560.

17. Saseendran S, Wysocki M, Varna J (2016) Evolution of viscoelastic behavior of a curing LY5052 epoxy resin in the glassy state, Advanced Manufacturing: Polymer \& Composites Science 2(2): 74-82.

18. Ghodhbani N, Maréchal P, Duflo H (2016) Ultrasound monitoring of the cure kinetics of an epoxy resin: Identification, frequency and temperature dependence. Polymer Testing 56: 156-166.

19. Dimopoulos A, Skordos AA, Partridge IK (2012) Cure kinetics, glass transition temperature development, and dielectric spectroscopy of a low temperature cure epoxy/amine system. Journal of Applied Polymer Science 124(3): 1899-1905.

20. Suzuki K, Miyano Y, Kunio T (1977) Change of viscoelastic properties of epoxy resin in the curing process, Journal of Applied Polymer Science 21(12): 3367-3379.

21. Plazek DJ, Chay IC (1991) The evolution of the viscoelastic retardation spectrum during the development of an epoxy resin network, Journal of Polymer Science: Part B: Polymer Physics 29(1): 17-29.

22. Shalini V, Revathi A (2017) Tensile and viscoelastic properties of epoxy-carbon nanotube nano-composites. Indian Journal of Advances in Chemical Science S2: 19-22.

23. Redaelli F, Sorbona M, Rossi F (2017) Bioresorbable polymers for biomedical applications, Edited by Giuseppe Perale and Jöns Hilborn, Woodhead Publishing, Cambridge, UK.

24. Brostow W, Goodman SH, Wahrmund J (2014) Handbook of Thermoset Plastics, Edited by Hanna Dodiuk and Sidney H. Goodman, William Andrew Publishing.

25. Seyhan AT, Gojny FH, Tanoglu M, Chulte K (2007) Rheological and dynamic-mechanical behavior of carbon nanotubes/vinyl esterpolyester suspensions and their nano-composites. European Polymer Journal 43: 2836-2847.

26. Angulo RO, Illescas JF, Aguilar PJ, Vargas CA, Haro CP (2018) Gel Point Determination of TEOS-based polymeric materials with application on conservation of cultural heritage buildings. Advances in Condensed Matter Physics.

27. Johnson LM, Huffman ND (2016) Rheology of epoxy-thermoplastic blends. In: Parameswaranpillai J, Hameed N, Pionteck J, Woo E (eds), Handbook of Epoxy Blends. Springer, Cham.

28. O’Brien DJ, Mather PT, White SR (2001) Viscoelastic properties of an epoxy resin during cure, Journal of Composite Materials 35(10): 883904.

29. Mitchell CA, Bahar JL, Arepalli S, Tout JM, Krishnamoorti R (2002) Dispersion of functionalized carbon nanotubes in polystyrene. Macromolecules 35: 8825-8830.

30. Salam MBA, Hosur MV, Zainuddin S, Jeelani S (2013) Improvement in mechanical and thermo-mechanical properties of epoxy composite using two different functionalized multi-walled carbon nanotubes. Open Journal of Composite Materials 3(2): 1-9. 
31. Kim JA, Seong DG, Kang TJ, Youn JR (2006) Effects of surface modification on rheological and mechanical properties of CNT/epoxy composites. Carbon 44(10): 1898-1905.

32. Song YS, Youn JR (2005) Influence of dispersion sates of carbon nanotubes on physical properties of epoxy nano-composites. Carbon 43(7): 1378-1385.
33. Misak HE, Widener CA, Burford DA, Asmatulu R (2014) Fabrication and Characterization of CNT-Aluminum Nanocomposites on 2024-T3 Al Substrates via Friction Stir Welding Process, Journal of Engineering Materials and Technology 136: 24501-24505.

\section{Your next submission with Juniper Publishers will reach you the below assets}

- Quality Editorial service

- Swift Peer Review

- Reprints availability

- E-prints Service

- Manuscript Podcast for convenient understanding

- Global attainment for your research

- Manuscript accessibility in different formats ( Pdf, E-pub, Full Text, Audio)

- Unceasing customer service

Track the below URL for one-step submission https://juniperpublishers.com/online-submission.php 